\title{
PEDAGOGÍAS CRÍTICAS: CRITERIOS PARA UNA FORMACIÓN DE DOCENTES EN INVESTIGACIÓN PEDAGÓGICA*
}

\author{
Juan Esteban Santamaría-Rodríguez 1 (1) \\ Claudia Rocío Benítez-Saza ${ }^{2}$ (1) \\ SCARLET Sotomayor-TaCuri ${ }^{3}$ (D) \\ Luis Alfonso Barragán-Varela ${ }^{4}$ (D)
}

\begin{abstract}
RESUMEN: El artículo propone una formación (Bildung) de docentes en investigación pedagógica desde las pedagogías críticas. Para ello, expone los fundamentos de la teoría crítica desarrollados por las Escuelas de Budapest y Frankfurt; y de igual modo, presenta el sustrato conceptual de estas pedagogías en dicha teoría, así como en las tensiones ideológicas (semiformación (Halbblidung), industria cultural) que las originan en Norte y Latinoamérica. El documento concluye con la exposición de los criterios para esta formación (Bildung) sugiriendo una apuesta curricular democratizadora orientada a investigar la práctica pedagógica del docente, propiciando su reflexión y favoreciendo la construcción de saber pedagógico como posibilidad para la emancipación de los agentes pedagógicos en el acto educativo y en su realidad.
\end{abstract}

Palabras claves: Formación docente. Investigación pedagógica. Saber pedagógico. Pedagogía crítica. Teoría crítica. Semiformación.

\section{PEDAgOgIA CRÍtICA: CRITÉRIOS PARA A FORMAÇÃO DE PROFESSORES EM PESQUISA PEDAGÓGICA}

RESUMO: Este artigo propóe a formação de professores (Bildung) em pesquisa pedagógica baseada em pedagogia crítica. Para tanto, expóe os princípios da teoria crítica das Escolas de Budapeste e de Frankfurt; da mesma forma, apresenta o substrato conceitual pedagógico nessa teoria, bem como nas tensôes ideológicas (semiformação (Halbblidung), indústria cultural) que as originam na América do Norte e na América Latina. O documento termina com a apresentação dos critérios para essa

\footnotetext{
*Artículo resultado del proyecto de investigación Fundamentos curriculares para una pedagogía de la teología desde la pedagogía critica y la teología de la liberación.

${ }^{1}$ Facultad de Teología. Universidad Santo Tomás - Bogotá, Colombia. E-mail: juanessantrax87@gmail.com

${ }^{2}$ Universidad Distrital Francisco José de Caldas - Bogotá, Colombia. E-mail: sazarocio@gmail.com

${ }^{3}$ Investigadora independiente - Bogotá, Colombia. E-mail: scarletsotomayor@hotmail.com

${ }^{4}$ Corporación Universitaria Minuto de Dios (UNIMINUTO) - Bogotá, Colombia.

E-mail: luis.bavalog@gmail.com

DOI: 10.1590/ES0101-73302019193786
} 
formação (Bildung), sugerindo um propósito curricular democratizante orientado a investigar a prática pedagógica dos professores, contribuindo para a sua reflexão e favorecendo a construção do conhecimento pedagógico como possibilidade de emancipação dos agentes pedagógicos no ato educativo e na sua realidade.

Palavras-chave: Formação de professores. Pesquisa Pedagógica. Conhecimento Pedagógico. Pedagogia Crítica. Teoria crítica. Semiformação.

\section{Critical PEDAgogies: CRiteria FOR TEACHER TRAINING IN PEDAGOGICAL RESEARCH}

ABSTRACT: This article proposes teacher training (Bildung) in pedagogical research based on critical pedagogies. For this purpose, it exposes the principles of the Budapest and Frankfurt Schools' critical theory; similarly, it presents the conceptual substrate of these pedagogies in that theory, as well as in the ideological tensions (semi-formation (Halbblidung), cultural industry) that originate them in North and Latin America. The document ends with the presentation of the criteria for this training (Bildung), suggesting a democratizing curricular purpose oriented to investigate the teachers' pedagogical practice, contributing to their reflection and favoring the construction of pedagogical knowledge as a possibility for the emancipation of the pedagogical agents in the educational act and in their reality.

Keywords: Teacher training. Pedagogical research. Pedagogical knowledge. Critical pedagogy. Critical theory. Semi-formation.

\section{Introducción}

$\mathrm{F}$

ormar docentes en investigación pedagógica implica reconocer las características de los procesos de enseńanza y aprendizaje que lo definen en la actualidad. Esto exige aproximarse a sus criterios teórico-práxicos, y a algunas "formas de hacer investigación, pues el estudiante, por una parte, aprende a investigar haciendo investigación" y, de otro lado, permite "lograr en la persona el desarrollo de la autonomía de su pensamiento, su libertad y su capacidad crítica” (MARÍN, 2016, p. 21).

Lo anterior es fundamental con miras a revisar el sentido que asume esta práctica pedagógica, su significado y su oportunidad para construir saber pedagógico desde ella misma. Es más, es una posibilidad para rescatar su "saber pedagógico presente en las prácticas educativas” (HERRERA-GONZÁLEZ, 2010, p. 60), buscando con ello apropiar su significado y sus apuestas transformativas en relación con el currículo, la didáctica, la evaluación y las mediaciones, entre otros aspectos pedagógicos y educativos. 
Sobre estos presupuestos, este artículo hace énfasis en la concepción pedagógica de dicha formación docente a través de un ejercicio de revisión documental. Así pues, y con la premisa de posicionar la escuela como escenario de investigación y transformación social (MCLAREN, 2005, p. 33), esta revisión considera cómo desde la pedagogía crítica dicho proceso formativo (Bildung) es propicio para la emancipación de los agentes pedagógicos, la apropiación crítica de su práctica pedagógica, y como posibilidad para transformar las hegemonías que condicionan la escuela como lugar de reproducción social.

\section{Pedagogía crítica: emergencia histórico-conceptual y horizonte práxico}

\section{Emergencia histórico-conceptual: nociones de una teoría crítica de la sociedad}

El horizonte conceptual de la pedagogía crítica se sustenta en la teoría crítica desarrollada por las Escuelas de Frankfurt y de Budapest (MALDONADO, 2011, p. 19-30). Así pues, es importante señalar sus presupuestos epistemológicos como base para comprender una pedagogía crítica que se asume como praxis y resistencia cultural en el marco escolar.

La escuela de Budapest abre un camino: comprender y actuar. Comprender lo universal e histórico y actuar en lo singular; lo macro y lo micro, lo personal y lo social para pensar, sentir y actuar adecuadamente; inducir formas democráticas de participación, interacción, lenguaje y comunicación en ambientes de aprendizaje más abiertos [...].

La escuela de Frankfurt [pretende] [...] la liberación del sujeto del marco clásico del saber proveniente de las ciencias empíricas o naturales, razón por la cual suele identificársele como escuela o teoría crítica. Por supuesto, su praxis crítica no sólo se despliega contra el positivismo, sino que, además, asume posturas de análisis crítico y de relectura frente al marxismo, al psicoanálisis, a la hermenéutica, a la lingüística y a la educación, entre otras disciplinas (MALDONADO, 2011, p. 22).

Estas dos escuelas convergen en asuntos fundamentales. De un lado, generan procesos de concientización en el orden económico, social y político. Por otra parte, consideran el empoderamiento de los sujetos y la transformación de la sociedad en dependencia de una lectura crítica sobre su configuración ideológica. Y finalmente, posicionan estas necesidades desde la praxis del sujeto en su localidad.

Con el interés de corroborar lo anterior, de la Escuela de Budapest es prudente resaltar las bases que le otorga Ferenczi. Su propuesta psicoanalítica 
infiere el surgimiento de una noción crítica opuesta a las lógicas modernistas y bélicas de la sociedad de la primera mitad del siglo XX. Al respecto se afirma: "[his] personality and views had a profound influence on the characteristics of the school, for he was a liberal and innovative thinker, tolerant toward different views and personalities, and averse to authoritarian attitudes" (RITTER, 2015, p. 43). Meszaros también profundiza en su herencia intelectual señalando aspectos como el siguiente:

Certain characteristics of the Budapest School began to gel, in particular, its interdisciplinary organization and openness and the presence of what were called lay analysts, thus resulting in its members each approaching psychoanalysis from a different perspective and, at the same time, each applying ideas from psychoanalysis to her or his own scholarly field (MESZAROS, 2013, p. 33).

Esta apreciación corrobora sus características como escuela de pensamiento psicoanalítico y multidisciplinar de carácter crítico (MESZAROS, 1998, p. 207-214). Ahora bien, aquella no se reduce a la teoría psicoanalítica de Ferenzci, en su columna vertebral está Lukács quien sienta sus bases desde una teoría política y filosófica a propósito del marxismo en tiempos de dominación soviética. Junto a él, Heller y Féher son también precursores de esta corriente de pensamiento crítico y su proyecto de sociedad no alienada al estrado soviético, estableciendo una postura dialéctica frente a la absolutización del mercado, los factores de exclusión y de desigualdad social de las sociedades configuradas bajo este régimen (KRIZAN \& KIESCHE, 1985, p. 43).

Ante el perfil de esta posición filosófica de partida de la "Escuela de Budapest”, se hace comprensible y plausible su crítica científico-política de lo que ellos llaman "sociedades de tipo soviético". Dado que la crítica trasciende el campo del sistema político penetrando la esfera cultural, especialmente la vida cotidiana, el enfoque de los autores puede ser calificado de antropológico, en consonancia con su interpretación de ellos mismos (KRIZAN \& KIESCHE, 1985, p. 46).

Por su parte, la Escuela de Frankfurt asume una praxis de reflexión crítica y dialéctica para cuestionar las estructuras hegemónicas de la sociedad. En ella, es posible señalar cómo aquellas son concebidas a modo de "industria cultural" vinculada a la masificación de los objetos sociales y su producción bajo el cultivo constante de la heteronomía de los sujetos (ADORNO, 2005, p. 5). Así pues, esta teoría devela el orden racional-instrumental que alienan el ser y quehacer del ser humano en la sociedad; $y$, por otra parte, abre un horizonte intelectual y político para la emancipación del sujeto a estos dos niveles. Para ello, apela a su capacidad de autoconocimiento con miras a una praxis histórica que busca la transformación del orden instrumental del saber y de la sociedad. 
El autoconocimiento del hombre en el presente no consiste, sin embargo, en la ciencia matemática de la naturaleza, que aparece como logos eterno, sino en la teoría crítica de la sociedad establecida, presidida por el interés de instaurar un estado de cosas racional (HORKHEIMER, 2003, p. 232).

Esta apreciación permite concebir la teoría crítica como una estructura racional que cuestiona las formas hegemónicas de sociedad, regidas por un condicionamiento industrial que aliena al ser humano hacia sus intereses científicos (positivistas) y económicos (HORKHEIMER, 2003, p. 149). De ello deriva que tal teoría no es un puro ejercicio filosófico, es una praxis racional que intelige la estructura económica y social de la realidad de cara a su posicionamiento dialéctico y su transformación. Es, entonces, una praxis histórica que establece un estado de cosas racional desde la posibilidad para revertir el logos eterno de la sociedad debido a que "la realidad es idealizada a través de procedimientos matemáticos; [y] por consiguiente, todo lo que es matemáticamente demostrado es universalmente cierto y pertenece a la realidad verdadera de la naturaleza" (BÓRQUEZ, 2012, p. 172).

Estos aspectos dan cuenta de la pertinencia de esta Escuela frente a la absolutización del positivismo en el ámbito de la ciencia y al instrumentalismo de la razón en la vida social (HORKHEMIER, 2003, p. 230; MANSILLA, 2014, p. 25). Así mismo, resaltan su identidad como discurso que pretende una praxis emancipatoria desde el empoderamiento de los sujetos, ya que es una teoría que "se opone a los hábitos dominantes del pensamiento, que contribuyen a la sobrevivencia del pasado y cuidan de los negocios de un orden perimido" (HORKHEIMER, 2003, p. 250), buscando revertir su condicionamiento histórico y social.

La teoría crítica de la Escuela de Frankfurt constata la urgencia permanente por cuestionar y revertir las macro-estructuras científicas, económicas, políticas y sociales toda vez que parte "de una idea del intercambio mercantil simple determinada por conceptos relativamente generales" (HORKHEIMER, 2003, p. 256). De igual manera, debido a sus tendencias de alienación en tanto formas de dominación ideológica para la conciencia y el ser del sujeto en su realidad histórica. Con lo anterior, puede afirmarse cómo "la adaptación o acomodación amenaza convertirse, bajo el predominio social de la racionalidad instrumental, en el criterio único al que puede acogerse cualquier comportamiento subjetivo" (GONZÁLEZ, 2002, p. 289, grifos del original). Sobre este presupuesto, es posible comprender cómo esta teoría pretende una realización práxica estableciendo una postura dialéctica frente al orden establecido ya que

constituye un alegato en el sentido de que es posible y recomendable una posición que supere el relativismo axiológico, que logre una visión realmente crítica de la totalidad social y que, aunque sea muy precariamente, seńale el derrotero de una praxis razonable (MANSILLA, 2005, p. 77). 
La teoría crítica como proyecto histórico-político constata una concepción pluralista de sociedad que supera su razón lógico-formal. Del lado de la Escuela de Budapest el análisis psicoanalítico y socio-político de la sociedad frente a la alienación del estrado soviético es fundamental (BROWN, 2011, p. 23), sin perder de vista que su crítica a la lógica industrial y su oposición al rechazo del humanismo como principio para el desarrollo humano establece una postura dialéctica ante tal estructura socio-política de apariencia premoderna (KRIZAN \& KIESCHE, 1985, p. 45-46). Y, por parte de la Escuela de Frankfurt, es determinante la praxis transformadora del orden instrumental de la sociedad a partir de la praxis reflexiva y autónoma del sujeto (GUR-ZE’EV, 1998, p. 464-465).

Ahora bien, tomando en consideración las características emancipadoras y práxicas de esta teoría crítica con respecto a los postulados desarrollados desde el idealismo kantiano hasta el surgimiento de epistemes contextuales, es preciso dar razón de su apropiación y el significado que tiene para la concepción de una pedagogía crítica. Pedagogía que, entre varios aspectos, es asumida como dinamismo transformador de la escuela y la práctica pedagógica en oposición al modelo industrial-cultural que la determina como espacio semiformativo (Halbblidung) a nivel histórico, social y político, y a su vez, determinado por el control del conocimiento y la cultura (ZAMORA, 2009, p. 38).

\section{Horizonte práxico: pedagogías críticas en clave norteamericana y latinoamericana}

La teoría crítica de las Escuelas de Budapest y Frankfurt es base epistemológica para la pedagogía crítica al marcar el derrotero del acto educativo como escenario para la emancipación intelectual, social y democrática de sus protagonistas en su entorno histórico-cultural (MCLAREN, 2015, p. 51). Sin perder de vista que esta pedagogía tiene su origen en el contexto europeo desde los precursores de estas escuelas y sus prácticas pedagógicas de resistencia (MALDONADO, 2011, p. 19), es preciso exponer su desarrollo en el continente americano en virtud de sus implicaciones sociales y políticas.

En este sentido, un primer elemento a tener en cuenta es el siguiente: "The Frankfurt School's theory of culture also offers a new concepts and categories for analyzing the role that schools play as agent of social and cultural reproduction" (GIROUX, 1983, p. 30). A consecuencia de ello, esta pedagogía es dialéctica al reconocer que este tipo de escuela está inserta en sociedades tecnocráticas reproductoras de patrones sociales y culturales definidos por las macro-estructuras económicas y científicas herederas del paradigma positivista. Lo anterior hace de esta pedagogía una posibilidad para la emancipación de sus agentes señalando un modo para apropiar y transformar la realidad bajo un criterio de concienciación que se opone a las tendencias pedagógicas de enmascaramiento y sometimiento 
de los agentes pedagógicos a una minoría de edad en su capacidad intelectual y social (ADORNO, 1998, p. 122-123). De ahí, entonces, que pueda considerarse cómo "el aula [...] se puede convertir en lugar de resistencia, donde los estudiantes combinen las posibilidades contrarias y transgresoras halladas en la cultura de la calle" (GIROUX, 1997, p. 67).

Esta pedagogía apuesta por una escuela como escenario de construcción social y para la realización de los sujetos como intelectuales transformativos (GIROUX, 2013, p. 19-21; GIROUX, 2016, p. 358). Con ello, busca revertir no solo las relaciones de dominación que existen entre profesores y estudiantes al establecer condiciones de aprendizaje que procuran la construcción del conocimiento, su identidad como agentes políticos, y la concepción de su praxis transformadora (MALDONADO, 2011, p. 22); sino también un constante proceso de emancipación (concienciación) en oposición a las ideologías de dominación que rigen la organización de la sociedad (ADORNO, 1998, p. 96).

En cabeza de Freire, esta pedagogía concientiza a los sujetos frente a su realidad histórica, busca su alfabetización, y desarrolla su capacidad crítica (REQUEJO, 2000, p. 132-135). Su apuesta es transformar el acto educativo desde la humanización, concienciación, resistencia y emancipación de sus agentes. En sus palabras, argumenta que "a educação, como formação, como processo de conhecimento, de ensino, de aprendizagem, se tornou, ao longo da aventura no mundo dos seres humanos uma conotação de sua natureza, gestando-se na história, como a vocação para a humanização" (FREIRE, 2001, p. 12). Lo anterior se hace explícito al reconocer que esta pedagogía supera la reproducción del conocimiento y la masificación de los sujetos, no sin desconocer sus implicaciones de acuerdo a su desarrollo histórico y social (ZUIN, 2014, p. 243-246).

Surgida del trabajo de Paulo Freire en el noreste brasileño, asolado por la pobreza en los ańos sesenta, la pedagogía crítica fusionó la ética de la teología de la liberación, y la teoría crítica de la escuela de Frankfurt, con los impulsos progresistas en educación. [...] Durante la siguiente década, la pedagogía crítica ejerció una gran influencia sobre la práctica pedagógica y sobre la formación del profesorado, así como sobre los trabajos académicos sobre sociopolítica y educación en todo el continente americano. En el siglo XXI, este campo se encuentra en una encrucijada conceptual, ya que sus investigadores e investigadoras contemplan la naturaleza del movimiento a una nueva fase de su evolución (KINCHELOE, 2008, p. 29-30).

El carácter ético de la teología de la liberación obedece a la concepción liberadora de la praxis eclesial, la cual emerge de su relación con los pueblos empobrecidos y excluidos a manos de los sistemas políticos dominantes en América Latina, impulsados en gran medida por los gobiernos estadounidenses (ELLACU- 
RÍA, 1987b, p. 255; SILVA, 2009, p. 95). Esta teología asume una hermenéutica crítica de la realidad histórica desde la experiencia de fe en Jesús y su correspondiente praxis de seguimiento (ELLACURÍA, 1987a, p. 16-21). No siendo tautológica, establece su saber en virtud de la "razonabilidad" de esta experiencia de fe histórica (GUTIÉRREZ, 1990, p. 58), la cual exige una praxis de liberación estructural y social de la realidad en clave de salvación eclesial.

La episteme de la teología de la liberación (GARCÍA, 2010, p. 288-290) ayuda a determinar esta pedagogía crítica gracias a su dinamismo intelectivo desde la praxis de fe. En ello, es posible apreciar la configuración de una praxis liberadora gracias a su "quehacer pedagógico" (ARCILA et al., 2015, p. 295), cuyo interés emancipatorio está encaminado hacia la transformación del acto educativo, de la escuela y de la sociedad.

Los aportes de las escuelas de Frankfurt y Budapest, y de la Teología de la Liberación convergen en una praxis histórica de resistencia y transformación en oposición a las tendencias de alienación económica, política y social determinadas por la ideología de mercado y su influencia en la masificación intelectual de los sujetos. Si bien estas corrientes teorico-práxicas difieren en su origen socio-crítico y hermenéutico, coinciden en su interés por transformar la realidad y procurar la emancipación/liberación desde la praxis de los sujetos (SANTOS, 2009a, p. 204-206; SANTOSb, 2009, p. 157-174). Praxis que, por demás, asume un carácter intelectual en resistencia a las tendencias de la industria cultural y la semiformación (Halbbildung) que someten el acto pedagógico formativo (Bildung) y sus implicaciones socio-políticas a criterios de sumisión, condicionamiento ideológico y dominación (GOMES, 2010, p. 241-244).

Kincheloe (2008) reitera su aporte a la pedagogía crítica toda vez que la praxis social y el análisis crítico de la realidad revierten su racionalidad instrumental, constituyéndose así en criterio para transformar éticamente el acto educativo como praxis emancipadora. Señala también cómo la formación de los docentes y el desarrollo de su práctica pedagógica implica su concienciación crítica desde la apropiación de su significado y repercusiones. En este sentido, no basta con afirmar que la pedagogía crítica emerge sobre la reflexión del acto educativo instrumental; su pretensión final es transformar la práctica pedagógica de sus condicionamientos ideológicos superando su identidad como transmisora de contenidos y reproductora de una cultura en términos de semiformación de los sujetos con respecto a ella (ADORNO, 2005, p. 15-16); y a su vez, llevándola hacia su significación como praxis pedagógica democrática (FREIRE, 2012, p. 111).

Finalizando las apreciaciones de Kincheloe (2008), la pedagogía crítica en el siglo XXI depende de su apropiación desde los contextos educativos. Esto exige comprender los lenguajes y significados de las prácticas pedagógicas para identificar sus perspectivas de transformación socio-política. De esta forma, ante una noción de pedagogía crítica, deben considerarse sus aristas con respecto 
a los contextos en los cuales emerge; y así mismo, al papel que allí desempeñan los agentes pedagógicos para su desarrollo y transformación (MALDONADO, 2011, p. 161-167).

\section{Contexto norteamericano: resistencia política y transformación cultural}

Giroux, McLaren y Apple, entre otros, dan razón de una pedagogía crítica concebida como política cultural, posibilidad democrática y resistencia social frente al entramado ideológico que recae en la escuela y la sociedad norteamericana (MCLAREN, 2005, p. 11-15). La escuela es escenario de reproducción cultural que legitima prácticas de formación para un sistema económico neoliberal. Es más, "están cada vez más dominadas por ideologías tecnicistas. Los programas curriculares, de enseńanza y de testeo más importantes, utilizadas por ejemplo en Estados Unidos, son sorprendentemente, casi todos de orientación conductista y reductivista” (APPLE, 1997, p. 116).

La realidad de la escuela norteamericana expone cómo el carácter crítico de la pedagogía se posiciona dialécticamente para confrontar su tendencia tecnocrática (APPLE, 2012, p. 39-53). Esta pedagogía desarticula la hegemonía que asegura la reproducción social y cultural desde la resistencia de sus agentes y la realización de sus deseos, anhelos y esperanzas. A nivel pedagógico, desdibuja sus nociones curriculares, sus comprensiones didácticas y los procesos educativos de igual índole, pues su base ideológica condiciona a la escuela como entidad reproductora del modelo de sociedad capitalista.

Diversos ámbitos conductistas de la escuela norteamericana demuestran que el modelo tecnocrático es propicio en una sociedad que produce bienes y servicios de consumo, reproduce patrones antropológicos específicos, y procura la participación política desde la imagen y no desde la praxis democrática. Así pues, es una escuela en donde la formación (Bildung) es reemplazada por una semiformación (Habbildung) como "forma social da subjetividade determinada nos termos do capital" (MAAR, 2003, p. 467), en donde atiende "al proceso de globalización en sus intentos por fomentar ciudadanos-consumidores dóciles que se identifican con los discursos y las prácticas del nacionalismo, el patriotismo y el individualismo" (MCLAREN \& FARAHMANDPUR, 2006, p. 130). Y, así mismo, sin posibilidad de una conciencia diferenciada que favorezca su emancipación intelectual, así como su capacidad para hacer apropiación de su realidad histórica en clave crítica e ilustrada.

Retomando las bases de la teoría crítica, la pedagogía crítica norteamericana cuestiona su modelo tecnicista de sociedad y de escuela (GIROUX, 2004 , p. 15), la racionalidad que sustenta el acto educativo y su apuesta por la reproducción social (GIROUX, 2004, p. 223-243; GIROUX, 2008, p. 17-22). 
Allí emerge su preocupación por establecer una praxis pedagógica que procure la emancipación de los agentes pedagógicos en virtud de su condición de "intelectuales transformativos" (GIROUX, 2013, p. 21). En este sentido, la noción crítica del acto educativo trasciende su estrado teórico hacia su dimensión práxica ya que asegura el empoderamiento de los sujetos para transformar el modelo de escuela hegemónico y configura una praxis de resistencia en clave de política cultural (GIROUX, 1997, p. 60).

En síntesis, puede apreciarse una impronta política, cultural y social en esta pedagogía. Su finalidad es la resistencia al modelo educativo y de sociedad neoliberal. Ahora bien, esta pedagogía pretende establecer procesos que atiendan a los intereses de los sujetos desde una perspectiva multicultural, incluyente y diversa (MCLAREN, 1994, p. 17-48) que supere su espectro tecnicista y favorezca la capacidad de agencia de aquellos.

\section{Contexto latinoamericano: pedagogías para la liberación}

En el contexto latinoamericano, la pedagogía crítica tiene su fundamento en el legado pedagógico de Paulo Freire. Teniendo en su base los postulados de la teoría crítica, esta pedagogía asume un carácter emancipatorio y liberacionista, cuyo punto de emergencia es la realidad de opresión a la cual es sometido el pueblo brasilero y latinoamericano debido a los condicionamientos de políticas capitalistas influenciadas por modelos tecnocráticos de desarrollo (KINCHELOE, 2008). En tal sentido, a continuación, es expuesta una comprensión de su propuesta pedagógica y su prospectiva como horizonte próximo para la transformación del acto educativo:

\footnotetext{
Parte de la vigencia de Freire está en cuanto, más que un método, nos aporta unas claves de lectura que a manera de alerta permanecen en quienes venimos de la tradición crítica, para evitar anquilosarnos e ir sobre la marcha haciendo las reelaboraciones necesarias. Y creo que, en el pensamiento de Freire, específicamente contrastado está este período del $80^{\prime}$ hasta su muerte con el periodo anterior, aparecen claramente cuatro grandes reconstrucciones: a. Una reconstrucción de la interpretación del nuevo contexto.

b. Una reconstrucción del proyecto emancipador.

c. Una reconstrucción de la pedagogía crítica.

d. Una reconstrucción de la educación popular (MEJÍA, 2011, p. 162).
}

Si bien su apuesta es por la educación para adultos, su alfabetización y concientización (FREIRE, 2012, p. 112), afirma también cómo el acto educativo debe ser dialéctico con respecto a las tendencias neoliberales del entrenamiento técnico de los sujetos (FREIRE, 2012, p. 166). Esto demuestra el carácter político 
de su praxis educativa y la distancia que toma frente a los intereses partidistas que asumen las riendas de la educación. Y de igual manera, su concordancia con la concepción de un acto pedagógico que se asume como formación cultural para el empoderamiento de los sujetos y no, como tendencia de cosificación del conocimiento de parte de las clases burguesas bajo la estructura de la industria cultural (IOP, 2009, p. 26).

Freire busca desarrollar una conciencia crítica ante la invasión tecnológica que recae sobre la educación, no porque la tecnología sea nociva en sí misma, sino porque su uso atiende a la ética neoliberal que se impone en la sociedad capitalista del siglo XX y XXI, la cual va en detrimento del ser humano y su proyecto vital. Al respecto, es oportuno resaltar la forma como esta pedagogía crítica es concebida como pedagogía cultural, ya que ante "los inmensos recursos económicos y tecnológicos que movilizan" el acto educativo tecnocrático, esta pedagogía está en oposición a "la emoción y a la fantasía, al sueño y a la imaginación" (SILVA, 1999, p. 73) y sus efectos para la inconciencia de los sujetos.

A decir verdad, necesitamos un saber técnico real, con el que podamos responder a los desafíos tecnológicos. Un saber que se reconoce como parte de un universo mayor de saberes. Un saber que no censura las preguntas legítimas que se formulan respecto de él: a favor de qué o de quién; contra qué o contra quién se utiliza. Un saber que no se reconoce indiferente a la ética y a la política, pero sí a la ética del mercado y a la política de esa ética (FREIRE, 2012, p. 161).

Freire está interesado en transformar la realidad a partir del proceso de concienciación de los sujetos. Según esto, puede inferirse que "à pedagogia crítica freiriana [...] consiste de um conjunto de teorias e práticas fundadas na educação como forma de emancipação e um projeto para a libertação política e social para um mundo sem opressão" (FERNANDES, 2016, p. 482). Estas perspectivas exponen la concepción de un acto educativo crítico, reflexivo y práxico, que desarrolla una postura profética de denuncia ante su condicionamiento político-social; y al mismo tiempo, de anuncio de su esperanza desde la concienciación de los pueblos marginados (FREIRE, 2012, p. 155).

Lo anterior es explícito al señalar su carácter democrático (FREIRE, $1997 a$, p. 84). Según esto, no puede haber una pedagogía crítica que no establezca vínculos concretos con la sociedad, así como tampoco si no se presenta como un estrado público y de acceso a todos, "ou seja, uma multiplicidade de formas de conhecimento que servirão para produzir identidades e subjetividades" (CASTRO, 2014, p. 580). Este aspecto es determinante en el proyecto emancipador de Freire y de la pedagogía crítica latinoamericana, pues sus formas de resistencia son una esperanza desde la práctica pedagógica, la cual se mantiene en 
tensión frente al carácter excluyente de modelos educativos tecnicistas y de cuño neoliberal (FREIRE, 2012, p. 148).

Un último aspecto a considerar, a propósito de esta pedagogía crítica latinoamericana, es la reconstrucción de la educación popular (MEJÍA, 2011, p. 162). Este aspecto trasciende los límites de la escuela formal, posibilita la instauración de procesos pedagógicos desde las comunidades, y visibiliza un proyecto de formación ético-política que no depende de la transmisión de contenidos como sí de las experiencias y saberes de sus protagonistas (FREIRE, 1997a, p. 88-89; SILVA, 1999, p. 31). A este respecto, Mejía (2011, p. 65) señala cómo "la educación popular coloca un gran énfasis en los procesos específicos de la pedagogía gestados en los aprendizajes y se descentra de ella misma para iniciar una reflexión en torno a ¿qué es una relación educativa?”.

Así las cosas, atendiendo al carácter semiformativo (Habbildung) que adquieren los procesos pedagógicos con herencia tecnocrática, la pedagogía crítica latinoamericana abre un horizonte para su transformación. Si bien existe una clave emancipatoria a modo de educación popular según propone Mejía (2011), otras posibilidades existen con respecto a la constitución de un acto pedagógico crítico que busca la formación cultural (Bildung) con implicaciones políticas, históricas y sociales de los sujetos con respecto a su contexto (PUCCI, 2001, p. 5-8).

Estos presupuestos permiten inferir cómo la pedagogía crítica latinoamericana, siendo heredera de su realidad histórica, asume un carácter dialéctico frente a las formas de condicionamiento socio-político de la cultura, la escuela y del acto educativo. Freire expone la estructura de una pedagogía crítica latinoamericana preocupada por la emancipación política de los sujetos desde su concienciación. Y, a su vez, como una posibilidad que se abre paso en el transcurso de la historia desde su carácter profético, procurando la liberación y el empoderamiento de los sujetos hacia su praxis democrática.

Atendiendo a su carácter emergente, es importante reiterar cómo esta pedagogía apela a las tensiones de la estructura social y al rol de los sujetos en ella (ORTEGA \& PEÑUELA, 2007, p. 96-99). Ejemplo de esto es la concepción de una pedagogía crítica para la formación ético-política de los docentes (RAMÍREZ-PARDO, 2012, p. 195), como resistencia a la globalización, al capitalismo cognitivo y a la hegemonía neoliberal (MEJÍA, 2010, p. 58-101, MEJÍA, 2007, p. 125-138; MEJÍA, 2001, p. 59-96), y en igual sentido, como posibilidad multicultural para la realización de los sujetos desde sus deseos, intereses y realidades (SILVA, 1999, p. 43-46).

\section{Formación de docentes en investigación pedagógica}

El carácter emancipador de las pedagogías críticas en el continente americano concibe un "quehacer pedagógico" dialéctico frente a las tendencias tecno- 
cráticas que condicionan la sociedad, la escuela y la práctica pedagógica. De cara a la problemática planteada, esta pedagogía cuestiona la formación de los docentes, pues "o discurso sobre o processo de formação humana declarava que ela se dava na relação dos sujeitos com os outros sujeitos sociais, tomando a natureza social como algo dado, naturalizado, determinado" (VILELA, 2006, p. 53). En igual sentido, indaga por dicha formación en el marco de la investigación pedagógica, principalmente en términos de apropiación histórico-contextual de la práctica pedagógica frente a su condicionamiento como escenario de semiformación, transmisión y reproducción cultural (SOUZA \& OLIVEIRA, 2012, p. 228-231).

Para tal fin, es preciso ampliar su noción curricular clásica hacia un horizonte experiencial del docente en su contexto en cuanto dinamismo y realidad cultural (SILVA, 1999, p. 33-36). Si bien esto no excluye su abordaje conceptual, sí trasciende su esquema instrumental, ya que "la pedagogía y las acciones educativas se convirtieron en objeto de estudio a partir de la preeminencia del método hipotético-deductivo" (HERRERA-GONZÁLEZ, 2010, p. 58) y su verificación experimental.

Ejemplo de ello es la pedagogía experimental como modelo de formación e investigación pedagógica (DE LA ORDEN, 2007, p. 13-15). Frente a esta formación apoyada en la codificación del conocimiento, es necesaria una postura pedagógica resistente que busque "a crítica do agir pedagógico [...] vigiando para que o espaço público do discurso em sala de aula se mantenha acessível a todos os concernidos" (MÜHL, 2011, p. 1047). Esto exige del acto educativo una reflexión crítica frente a la estructura tecnocrática que sostiene la formación de docentes como semiformación (MAAR, 2003; CORREIA, 2016). Y, paralelo a ello, una postura dialéctica ante prácticas formativas concebidas desde el capitalismo cognitivo (MEJÍA, 2010, p. 61-63).

Debe tenerse en cuenta que "no hay enseñanza sin investigación ni investigación sin enseñanza” (FREIRE, 1997b, p. 30). En términos de formación de docentes, esta enseñanza debe vincularse al desarrollo de su práctica pedagógica, pues es el contexto el que le otorga su significado (VILELA, 2006, p. 71-75). Esta reciprocidad permite articular un quehacer pedagógico emancipador en la misma práctica, dejando entrever que esta formación es procesual desde epistemes emergentes (MEJÍA, 2010, p. 86).

Ahora bien, teniendo en cuenta la tensión que existe por una formación de docentes desde el modelo tecnocrático y crítico, es preciso indagar por la investigación pedagógica en igual sentido. Bajo los presupuestos señalados, "a semiformação caracteriza-se como a conquista do espírito pela lógica do fetiche da mercadoria cultural" (ZUIN, 2014, p. 245), el cual, es reproducido en los intereses instrumentalistas de la investigación, y no en concordancia con su carácter emergente. En este sentido, debe aclararse que este tipo de investigación "tiene que ver con la comprensión de la complejidad que representa la enseñanza y con la disputa por la misma como objeto de investigación de todos los investigadores 
sociales" (CALVO; CAMARGO; PINEDA; 2008, p. 166), lo cual permite comprender su interés en hacer énfasis en la práctica pedagógica de los maestros y su posicionamiento como un campo de conocimiento.

Una de las tensiones ideológicas que afecta este carácter formativo radica en la consolidación de su objeto bajo un estatuto de cientificidad propio. En contraposición a esta lógica deductiva, su criterio depende del saber que emerge y se construye en la práctica del maestro. Ahora bien, aun cuando esta construcción posee dinamismos subjetivos, fruto de la localidad del docente en el aula, es objetiva desde la relevancia que tiene en los agentes pedagógicos gracias a la misma práctica, la reflexión construida, y su apropiación desde sus propios aprendizajes (DE TEZANOS, 2007, p. 12-13).

En este sentido, si la investigación pedagógica "articula la teoría y la práctica, no como dos campos distanciados entre los cuales se tienden puentes, sino como dos aspectos constitutivos de la misma realidad" (HERRRERA-GONZÁLEZ, 2010, p. 61), la construcción de este saber pedagógico debe considerar dichos aprendizajes y contextos como eje fundamental. Y, a la luz del presupuesto pedagógico crítico, tener en cuenta la interacción de los sujetos y las posibilidades de emancipación que brinda.

Estos elementos son base para una investigación pedagógica en clave crítica. De ello deriva un acto educativo que investiga y construye saber pedagógico desde la experiencia del docente en el aula más que desde la teoría pedagógica (RESTREPO, 2004, p. 47). Y, de igual modo, ayuda a superar sus tensiones ideológicas a propósito de su noción mecánica (fetichista), posibilitando así una formación contextualizada y crítica desde la realidad del aula y la cultura (GRUSCHKA, 2014, p. 4-7).

Tomando en consideración lo expuesto, es oportuno reiterar la superación del paradigma curricular clásico de este proceso formativo y su constante orientación hacia una noción empírica, racial, narrativa y étnica del mismo (SILVA, 1999, p. 51-54). Los dinamismos teórico-práxicos de la pedagogía crítica exigen "un currículo con perspectiva democratizadora, descentralizado, que sea autónomo y que permita la autonomía, que garantice la preparación para la acción social, que invite a la construcción de significados y contenidos" (RIPOLL; RIPOLL; VÁSQUEZ, 2016, p. 31). Siendo esto así, será propicia la transformación de la práctica pedagógica, del significado del aula de clase y de las relaciones entre los agentes pedagógicos desde su constante indagación y reflexión.

\section{Consideraciones finales}

Una formación de docentes en investigación pedagógica desde las pedagogías críticas en el contexto americano es posible al confrontar la concepción 
tecnicista del acto educativo y el sentido experimental de la investigación que lo sostiene. Siendo esto así, su eje central es la práctica pedagógica y su posibilidad crítico-reflexiva desde la apropiación del aprendizaje, el saber que puede construirse desde los agentes pedagógicos y los significados y tensiones que emergen en el aula escolar. Para ello, "é necessário que os envolvidos na pesquisa tenham em mente uma pregunta norteadora do processo: $\mathrm{O}$ que revela a sala de aula sobre a escola? ou Qual escola a sala de aula nos revela?" (VILELA; NOACK-NAPOLES, 2010, p. 319).

Aun cuando el carácter de la formación de los docentes asume una postura crítica, pretendiendo su emancipación intelectual, social y democrática, no puede perderse de vista que su finalidad es posibilitar su práctica pedagógica en igual sentido (VILELA, 2006). De ahí que sea un proceso de formación sincrónico que implica a los agentes pedagógicos desde el aula de formación y el aula de interacción. Esta relación dialógica de contextos demuestra cómo la investigación pedagógica no depende de una estructura metodológica específica, sino del proceso de concienciación de los agentes con respecto a su práctica pedagógica, su formación y los aprendizajes que allí surgen; y en igual sentido, a la realidad del aula y su tensiones históricas, sociales, políticas y humanas representadas desde sus actores. Así pues, este aspecto explicita la necesidad de "analizar las posibilidades de constituir una práctica capaz de permitir una acción emancipatoria que exceda a la crítica y que pueda instalarse como acción concreta de la experiencia escolar" (SGRÓ, 2001, p. 20).

Frente a la postura que asumen las Escuelas de Budapest y de Frankfurt con respecto al paradigma positivista de la ciencia y la configuración lógico-racional de la sociedad, una formación docente en investigación pedagógica en clave crítica transforma el sentido del acto educativo y del proceso investigativo desde el saber pedagógico que emerge, se construye y se sistematiza en contexto. La pedagogía crítica en el continente americano demuestra las tensiones que afectan la escuela como escenario de reproducción cultural y semiformación (Habbildung). Así pues, a partir de estas pedagogías se asume una formación (Bildung) como praxis que transforma la práctica investigativa en clave emergente e histórico-contextual sin perder de vista que este ámbito formativo lo constituye el aprendizaje situado (realidad cultural), las posibilidades de emancipación que emergen desde la construcción del conocimiento y, las oportunidades de transformación de la realidad escolar y social que de allí derivan.

\section{Referencias}

ADORNO, T. Educación para la emancipación: conferencias y conversaciones con Hellmut Becker (1959-1969). Madrid: Ediciones Morata, 1998.

ADORNO, T. Teoria da semicultura. Primeira versáo, v. XIII, n. 191, p. 1-18, 2005. Disponible en: $\leq$ https://goo.gl/bwxAuZ>. Acceso en: 20 jun. 2018. 
APPLE, M. Education and power. Nueva York: Routledge; Taylor and Francis Group, 2012. APPLE, M. Teoría crítica y educación. Buenos Aires: Miño y Dávila, 1997.

ARCILA, A. et al. La influencia de la teología de la liberación en el pensamiento pedagógico de Paulo Freire y de Luis Óscar Londoño Zapata. El Ágora USB, v. 15, n. 1, p. 291-305, 2015. Disponible en: <https://goo.gl/EK2tm7>. Acceso en: 6 mar. 2018. http://dx.doi. org/10.21500/16578031.15

BÓRQUEZ, R. Pedagogía crítica. México: Trillas, 2012.

BROWN, D. Toward a radical democracy. The political economy of the Budapest School. Nueva York: Taylor and Francis Group, 2011. Disponible en: <https:/goo.gl/ BEotah>. Acceso en: 5 feb. 2018.

CALVO, G.; CAMARGO, M.; PINEDA, C. ¿Investigación educativa o investigación pedagógica? El caso de la investigación en el Distrito Capital. Magis. Revista Internacional de Investigación en Educación, v. 1, p. 163-174, 2008. Disponible en: <http://www. redalyc.org/articulo.oa?id=281021687011>. Acceso en: 15 mar. 2018.

CASTRO, V. Pedagogias do presente. Educaçáo \& Realidade, v. 39, n. 2, p. 573-593, 2014. Disponible en: <https://goo.gl/V2Un6M>. Acceso en: $1^{\circ}$ jul. 2018. http://dx.doi. org/10.1590/S2175-62362014000200012

CORREIA, F. Theodor Adorno e o problema da (semi) formação. Kínesis - Revista de Estudos dos Pós-Graduandos em Filosofia, v. 8, n. 16, p. 110-126, 2016. Disponible en: <https://goo.gl/w3uxKe>. Acceso en: 28 jun. 2018.

DE LA ORDEN, A. El nuevo horizonte de la investigación pedagógica. Revista Electrónica de Investigación Educativa, v. 9, n. 1, p. 1-22, 2007. Disponible en: <http:// bit.ly/2I44TDq>. Acceso en: 13 mar. 2018.

DE TEZANOS, A. Oficio de enseñar - saber pedagógico: la relación fundante. Educación y Ciudad, v. 12, p. 7-26, 2007. Disponible en: <https://goo.gl/ayCk9U>. Acceso en: 25 mar. 2018.

ELLACURÍA, I. Aporte de la teología de la liberación a las religiones abrahámicas en la superación del individualismo y del positivismo. Revista Latinoamericana de Teología, El Salvador, v. 4, n. 10, p. 3-28, 1987a. Disponible en: <https://goo.gl/5xAuDt>. Acceso en: 6 mar. 2018.

ELLACURÍA, I. La teología de la liberación frente al cambio sociohistórico de América Latina. Revista Latinoamericana de Teología, El Salvador, v. 4, n. 12, p. 241-236, 1987b. Disponible en: <https://goo.gl/pxKyWf $>$. Acceso en: 19 feb. 2018.

FERNANDES, S. Pedagogia crítica como práxis marxista humanista: Perspectivas sobre solidariedade, opressão e revolução. Educaçáo e Sociedade, v. 37, n. 135, p. 481-496, 2016. Disponible en: <https:/goo.gl/NpU7mV>. Acceso en: 22 feb. 2018. http://doi. org/10.1590/ES0101-73302016140795

FREIRE, P. La educación como práctica de la libertad. 45. ed. México: Siglo XXI, 1997a.

FREIRE, P. Pedagogía de la autonomía: saberes necesarios para la práctica educativa. México: Siglo XXI, 1997 b. 
FREIRE, P. Pedagogía de la indignación: cartas pedagógicas en un mundo revuelto. Buenos Aires: Siglo XXI, 2012.

FREIRE, P. Política e Educação: Ensaios. 5. ed. São Paulo: Cortez, 2001.

GARCÍA, J. La epistemología de la teología de la liberación y su hermenéutica desde la praxis. TELOS. Revista de Estudios Interdisciplinarios en Ciencias Sociales, v. 12, n. 3, p. 287-297, 2010. Disponible en: <https://goo.gl/5L4jBq >. Acceso en: 6 mar. 2018.

GIROUX, H. Introducción: Democracia, educación y política en la pedagogía crítica. In: MCLAREN, P.; KINCHELOE, J. (eds.). Pedagogía crítica. De qué hablamos, dónde estamos. Barcelona: Graó, 2008. p. 17-22.

GIROUX, H. La pedagogía crítica en tiempos oscuros. Praxis Educativa, v. 17, n. 1-2, p. 13-26, 2013. Disponible en: <https://goo.gl/KLwBgd>. Acceso en: 15 feb. 2018.

GIROUX, H. La pedagogía radical como política cultural: Más allá del discurso de la crítica y el antiutopismo. En: MCLAREN, P. (ed.). Pedagogía crítica y cultura depredadora. Barcelona: Paidós, 1997. p. 47-77.

GIROUX, H. Teoría y resistencia en educación. Una pedagogía para la oposición. 6. ed. México: Siglo XXI, 2004.

GIROUX, $H$. Theory and practice in educational administration. Critical theory and educational practice. Victoria: Deakin University, 1983.

GIROUX, H. When schools become dead zones of the imagination: A critical pedagogy manifesto. High School Journal, v. 99, n. 4, p. 351-359, 2016. Disponible en: <https:// eric.ed.gov/?id=EJ1104152>. Acceso en: 2 feb. 2018.

GOMES, R. Teoria crítica da sociedade e o sentido político da educação. Linhas Críticas, v. 16, n. 31, p. 239-258, 2010. Disponible en: shttps://goo.gl/hKH23M>. Acceso en: 23 jun. 2018 .

GONZÁLEZ, J. La teoría crítica de la Escuela de Frankfurt como proyecto histórico de racionalidad revolucionaria. Revista de Filosofía, v. 27, n. 2, p. 287-303, 2002. Disponible en: $\leq$ https://goo.gl/aN23R6>. Acceso en: 13 feb. 2018.

GRUSCHKA, A. Teoria crítica e pesquisa empírica em educação: A escola e a sala de aula. Constelaciones. Revista de Teoría Crítica, v. 6, n. 6, p. 3-31, 2014. Disponible en: <https://goo.gl/1NKNEC>. Acceso en: 29 jun. 2018.

GUR-ZE'EV, I. Toward a nonrepressive critical pedagogy. Educational Theory, v. 48, n. 4, p. 463-486, 1998. Disponible en: <https://goo.gl/J3oP5k>. Acceso en: 10 feb. 2018. https://doi.org/10.1111/j.1741-5446.1998.00463.x

GUTIÉRREZ, G. Teología de la liberación. Perspectivas. Salamanca: Sígueme, 1990.

HERRERA-GONZÁLEZ, J. La formación de docentes investigadores: el estatuto científico de la investigación pedagógica. Magis: Revista Internacional de Investigación en Educación, v. 3, n. 5, p. 53-62, 2010. Disponible en: <http://www.redalyc.org/ articulo.oa?id=281023476003>. Acceso en: 5 mar. 2018.

HORKHEIMER, M. Teoría crítica. Buenos Aires: Amorrortu, 2003. 
IOP, E. Formação cultural, semicultura e indústria cultural: contribuiçóes de Adorno sobre a emancipação. Espaço Pedagógico, v. 16, n. 2, p. 20-33, 2009. Disponible en: <https:// goo.gl/EDepML>. Acceso en: 30 jun. 2018. https://doi.org/10.5335/rep.2013.2212

KINCHELOE, J. La pedagogía crítica en el siglo Xxi: evolucionar para sobrevivir. In: MCLAREN, P.; KINCHELOE, J. (eds.). Pedagogía crítica. De qué hablamos, dónde estamos. Barcelona: Graó, 2008. p. 25-69.

KRIZAN, M.; KIESCHE, E. Dictadura sobre las necesidades. La Escuela de Budapest. Nueva Sociedad, v. 80, p. 41-55, 1985. Disponible en: $\leq$ https:/goo.gl/YqGtfH>. Acceso en: 12 feb. 2018.

MAAR, W. Adorno, semiformação e educação. Educação e Sociedade, v. 24, n. 83, p. 459-476, 2003. Disponible en: <https://goo.gl/5azjcJ>. Acceso en: 25 jun. 2018. http://dx.doi.org/10.1590/S0101-73302003000200008

MALDONADO, M. Pedagogías críticas. Europa, América Latina, Norteamérica. 2. ed. Bogotá: Cooperativa Editorial Magisterio, 2011.

MANSILLA, H. Friedrich Nietzsche, la Escuela de Frankfurt y el posmodernismo. Revista de Filosofía, v. 51, p. 73-97, 2005. Disponible en: $\leq$ https://goo.gl/hNko3H>. Acceso en: 9 feb. 2018.

MANSILLA, H. Nuevos aportes de la Escuela de Frankfurt sobre los problemas de nuestro tiempo y su posible aplicación al Tercer Mundo. Trayectorias, v. 16, n. 38, p. 21-36, 2014. Disponible en: shttps://goo.gl/J6rrPg $>$. Acceso en: 31 ene. 2018.

MARIN, J. La investigación en educación y pedagogía. Sus fundamentos epistemológicos y metodológicos. Bogotá: USTA, 2016.

MCLAREN, P. La vida en las escuelas. Una introducción a la pedagogía crítica en los fundamentos de la educación. 4. ed. México: Siglo XXI, 2005.

MCLAREN, P. Pedagogía crítica, resistencia cultural y la producción del deseo. Buenos Aires: Ideas, 1994.

MCLAREN, P. Pedagogía crítica y lucha de clases en la era del territorio neoliberal. Revista Internacional de Educación para la Justicia Social, v. 4, n. 2, p. 29-66, 2015. Disponible en: <https:/goo.gl/RMbL4u>. Acceso en: 19 feb. 2018. http://dx.doi. org/10.15366/riejs2015.4.2

MCLAREN, P.; FARAHMANDPUR, R. La enseñanza contra el capitalismo global y el nuevo imperialismo: Una pedagogía crítica. Madrid: Editorial Popular, 2006.

MEJÍA, M. Educación(es) en la(s) globalización(es) I. Entre el pensamiento único y la nueva crítica. Bogotá: Desde Abajo, 2007.

MEJÍA, M. Educación y pedagogías críticas desde el sur (cartografías de la educación popular). Lima: CEAAL, 2011.

MEJÍA, M. Las pedagogías críticas en tiempos de capitalismo cognitivo. Cartografiando las resistencias en educación. Aletheia. Revista de Desarrollo Humano, Educativo y Social Contemporáneo, v. 2, n. 2, p. 58-101, 2010. Disponible en: <https://goo.gl/ LYkEZo>. Acceso en: 25 feb. 2018. 
MEJÍA, M. Latinoamericanizar las leyes de la globalización. In: TEDESCO, J. (ed.). Educación en la globalización. Ideas para la integración en educación presencial y a distancia. Medellín: Ateneo Porfirio Barba Jacob, 2001. p. 59-96.

MESZAROS, J. Ferenczi and Beyond: Exile of the Budapest School and Solidarity in the Psychoanalitic Movement During the Nazi Years. Great Britain: Karnac Books, 2013.

MESZAROS, J. The tragic success of European Psychoanalysis: "The Budapest School". International Forum of Psychoanalysis, v. 7, n. 4, p. 207-214, 1998. Disponible en:_https://goo.gl/o97sCG>. Acceso en: 8 feb. 2018. https://doi. org/10.1080/080370698436691

MÜHL, E. Habermas e a Educação: Racionalidade comunicativa, diagnóstico crítico e emancipação. Educaçáo e Sociedade, v. 32, n. 117, p. 1035-1050, 2011. Disponible en: <https://goo.gl/VZNJDo >. Acceso en: 9 mar. 2018. http://dx.doi.org/10.1590/S0101$\underline{73302011000400008}$

ORTEGA, P.; PENUUELA, D. Perspectiva ético-política de las pedagogías críticas. Folios, v. 26, p. 93-103, 2007. Disponible en: <https://goo.gl/pTfWYi . Acceso en: 20 feb. 2018. https://doi.org/10.17227/01234870.26folios93.103

PUCCI, B. Teoria crítica e educação: contribuições da teoria crítica para a formação do professor. Espaço Pedagógico, v. 8, p. 13-30, 2001. Disponible en: <https://goo.gl/ dEsYei>. Acceso en: 25 jun. 2018.

RAMÍREZ-PARDO, P. Las pedagogías críticas: un lenguaje de posibilidad para la universidad y sus maestros. Magis. Revista Internacional de Investigación en Educación, v. 5, n. 10, p. 189-202, 2012. Disponible en: <https://goo.gl/ShhKMT>. Acceso en: 10 feb. 2018.

REQUEJO, A. Conocer para transformar. In: CARBONELL, J. (ed.). Pedagogías del siglo XX. Barcelona: Cisspraxis, 2000. p. 131-142.

RESTREPO, B. La investigación-acción educativa y la construcción de saber pedagógico. Educación y Educadores, v. 7, p. 45-55, 2004. Disponible en: $\leq$ http://bit.ly/2I63vAi $>$. Acceso en: 30 jun. 2018.

RIPOLL, M.; RIPOLL, A.; VÁSQUEZ, F. La formación ciudadana en la escuela: Educandos críticos y activos. Inclusión \& Desarrollo, v. 3, n. 2, p. 24-33, 2016. Disponible en: <https://goo.gl/zWCgAR $>$. Acceso en: 9 mar. 2018. http://dx.doi. org/10.26620/uniminuto.inclusion.3.2.2016.24-33

RITTER, A. Theories of trauma transmission after Ferenczi: The unique contribution of Hungarian psychoanalysis. Canadian Journal of Psychoanalysis, v. 23, n. 1, p. 42-56, 2015. Disponible en: $\leq$ https://goo.gl/jcXc3d $>$. Acceso en: 3 feb. 2018.

SANTOS, M. En el límite revelador: de la desesperanza a la esperanza. Daimon Revista Internacional de Filosofía, v. 48, p. 187-206, 2009a. Disponible en: <https:/goo.gl/ wrxsAs>. Acceso en: 22 feb. 2018.

SANTOS, M. Los oprimidos como luz. Benjamin, Kafka, teología de la liberación. Revista de Filosofía, v. 34, n. 2, p. 157-174, 2009b. Disponible en: <https:/goo.gl/ Meer9f $>$. Acceso en: 23 feb. 2018. 
SGRÓ, M. Pedagogias críticas: repensando seus fundamentos e possibilidades. Educação. Revista do Centro de UFSM, v. 26, n. 2, p. 9-21, 2001. Disponible en: <https:/goo.gl/ pj8yMa . Acceso en: 18 jun. 2018. http://doi.org/10.5902/19846444

SILVA, S. La teología de la liberación. Teología y Vida, v. 50, p. 93-116, 2009. Disponible en: <https://goo.gl/fWYYcz>. Acceso en: 2 feb. 2018. http://dx.doi.org/10.4067/S0049$\underline{34492009000100008}$

SILVA, T. Documentos de identidad. Una introducción a las teorías del currículo. Belo Horizonte: Autêntica, 1999.

SOUZA, B.; OLIVEIRA, A. Formação cultural e semiformação: contribuiçóes de Theodor Adorno para pensar a educação hoje. Educaçáo, v. 35, n. 2, p. 225-232, 2012. Disponible en: <https://goo.gl/CdyfPT>. Acceso en: 30 jun. 2018.

VILELA, R. A Teoria Crítica da Educação de Theodor Adorno e sua apropriaçáo para análise das questóes atuais sobre currículo e práticas escolares. Relatório Final de Pesquisa 2004-2006 - Pontifícia Universidade Católica de Minas Gerais. Belo Horizonte, 2006. Disponible en: <https://goo.gl/Ex16oy>. Acceso en: 2 jul. 2018.

VILELA, R.; NOACK-NAPOLES, J. "Hermenêutica objetiva" e sua apropriação na pesquisa empírica na área da educação. Linhas Críticas, v. 16, n. 31, 2010. Disponible en: $\leq$ https://goo.gl/kPBVVB $>$. Acceso en: 23 jun. 2018.

ZAMORA, J. Th. W. Adorno: Aportaciones para una teoría crítica de la educación. Teoría de la Educación, v. 21, n. 1, p. 19-48, 2009. Disponible en: $\leq$ https://goo.gl/rB2nv9>. Acceso en: 20 jun. 2018.

ZUIN, A. A cultura digital, a semiformação e o novo elo pedagógico. Inter-Ação, Goiania, v. 39, n. 2, p. 241-256, 2014. Disponible en: <https://goo.gl/Zwh8T1>. Acceso en: 22 jun. 2018. https://doi.org/10.5216/ia.v39i2.31705 